$\underline{\text { ISSN 1466-1535 }}$

\title{
Qualifying for a job: an educational and economic audit of the English 14-19 education and training system
}

SKOPE Research Paper No.44 Spring 2004

Rosa Fernández, SKOPE, Department of Economics, University of Oxford

Geoff Hayward, SKOPE, Department of Educational Studies, University of Oxford 


\section{Editor's Foreword}

\section{SKOPE Publications}

This series publishes the work of the members and associates of SKOPE. A formal editorial process ensures that standards of quality and objectivity are maintained.

Orders for publications should be addressed to the SKOPE Secretary, SKOPE, Warwick Business School, University of Warwick, Coventry CV3 7AL 


\begin{abstract}
This paper seeks to address the issue of balancing the supply and demand side of the skills equation in Britain. The analysis of the supply of intermediate level qualifications reveals an increase in participation, retention and achievement in postcompulsory education, evidence of a fair degree of success of supply-side educational policies. The analysis of the balance between the supply and demand however, reveals some fatigue in the allocation of the increasing number of qualifications supplied by the labour force. Furthermore the increasing incidence of over-qualification in the labour market at intermediate levels of education casts doubt on the suitability of supply-side education policies based on qualifications and brings to mind the possibility that a turning point in the ability of the labour market to absorb an increasing number of qualifications may be approaching.
\end{abstract}




\section{Introduction}

Conventional wisdom amongst education and training policy makers in Britain is that within the UK economy skill demand exceeds supply. As a result, the story goes, the economy of the United Kingdom underperforms in terms of labour productivity compared with other competitor nations in the OECD, thereby thwarting the high skills vision for the UK economy and a fairer society. According to this way of 'framing and naming' the issue (Keep and Mayhew, 1999), the solution to economic underperformance is to increase the supply of skills into the economy. Education and training policy is consequently focused upon

'... a range of supply-side solutions ... that are dependent upon a number of managerial technologies. Examples include target setting and its associated planning mechanisms, and funding systems and their associated methodologies and incentive structures. The visible manifestation of a belief in the ability of these devices to deliver a high skills vision rests in the creation of the new Learning and Skills Council (LSC) and its statutory duty to set and pursue a fresh set of National Learning Targets. These targets form the overarching strategic focus for the management of the English [Education and Training] system.' (Keep, 2002: 458)

This ideological commitment to reform of the supply side of the skills equation, whilst ignoring the demand side, has a long history in Britain. Indeed, intervening on the supply side through education and training policy has become almost the only socially and politically acceptable way for British government policy to be used to raise the economic competitiveness of organisations. The result is a sidelining of other issues such as 'competitive strategies, labour market regulation, work organisation, job design, and the quality of working life' (Keep, 2002: 458) as being beyond the remit of public policy. The black box of the firm has remained firmly and tightly shut for the last two decades and, notwithstanding more recent policy analyses such as that undertaken by the Performance and Innovation Unit (PIU, 2001), is likely to remain so for the foreseeable future.

Education and training policy is also seen as the key lever through which to redress distributional imbalances with the United Kingdom. Notwithstanding important redistributional measures such as tax credits for poor working families, the poor are 
supposed to learn their way out of poverty with training seen as the primary means of alleviating economic distress and enhancing 'employability' skills. This is not just a British view but is echoed in other industrialised countries. For example, Lafer ${ }^{1}$ (2002: 2) provides the following as a summary of this policy perspective in the United States:

'The consensus behind training as a solution to economic distress is captured in a New York Times editorial issued as a call to action during the 1992 presidential campaign. After noting the dramatic increase in income inequality over the course of the 1980s, The Times offers the following analysis:

Economists are increasingly persuaded that this rising inequality cannot be explained by something as simple as greed [or] politics ... They look to something more deeply ingrained in modern industrialized economies - call it technology for short. The days when high school dropouts could earn high wages in manufacturing are gone. Modern economies more than ever require skilled, educated labor ... The modern industrial economy is calling out for skilled, educated workers ... The right way for Congress to respond is to promote the education of sophisticated workers. That means massive new commitments to ... training high school dropouts and welfare mothers.'

The supposed imbalance between skill supply and skill demand is usually explained in terms of failures in the allocative role of the labour market. A lack of communication between employers, on the one hand, and education and training providers, on the other hand, is often highlighted as a particular weakness in the UK system. Compared to many of our European neighbours, the UK has very poorly developed employer networks and organisations that can mediate the development of education and training policy at a local level. Consequently, the demand for skills is primarily communicated to the supply side via the state and, in the process, messages are refracted by state concerns into an emphasis on formal qualifications and graduation from formal programmes of education and training. Following the logic outlined by Keep (2002), performance targets are then set in terms of particular proportions of a population achieving certain levels of qualification. For example, the

\footnotetext{
${ }^{1}$ Lafer's critique is not aimed at the idea of providing people with better educational opportunities but rather at the idea that providing a better educated workforce will lead to both increased economic productivity and people to learn a better living in economies with an inadequate supply of decent, well paid jobs.
} 
National Learning Targets for England required that by 200260 per cent of 21 year olds should be qualified to Level 3 (see Table 1) and 85 per cent of 19 year olds should be qualified to Level 2. The assumption, then, is that the skills and acquired within the formal education and training system will then transfer into the workplace.

The dominant policy view in the United Kingdom remains, therefore, that the route to a more prosperous and equal society lies through education and training, and the acquisition of qualifications. In particular the view expressed by Tony Blair that ' $[i] n$ the long run, schools must play the central role in preparing people better for work and careers' (PIU, 2001:3) has been central to education and training policy for the last quarter of a century. As a result, the British education and training system have been subject to wave after wave of reform. Qualifications have changed repeatedly, funding mechanisms adjusted and complicated, targets set and regulatory organisations established. Systemic reform initiatives have been undertaken, calls for an even more demand led system made, and increased levels of competition between institutions implemented through the 'marketisation' of the education and training system - with the aim of matching skills supply more closely to the perceived demand for skills revealed by, for example, employer surveys.

Our purpose in this paper is to audit how successful education and training policy has been in terms of increasing the supply of qualifications into the economy over the last two decades and the economic consequences of this. We focus on the English 14-19 education and training system and qualification at Level 2 and 3 of the English National Qualification System (see Table 1). We first provide a statistical over view indicating how the performance of the 14-19 education and training system has changed over time in terms of participation and certification rates. We then examine the qualifications mix being produced by the system. Finally, we consider economic arguments for supply side education and training policies, and their potential consequences for labour market performance. 


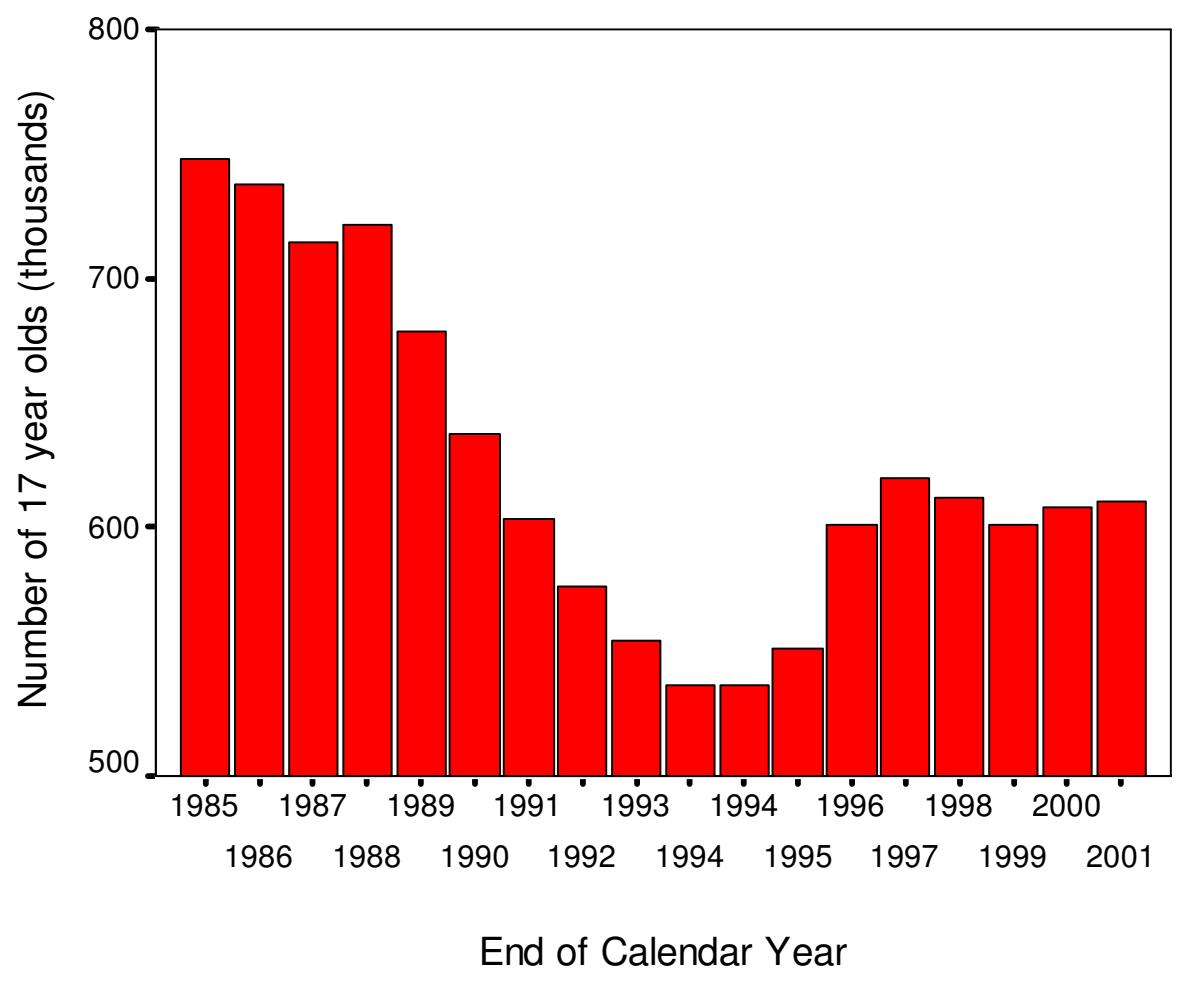

Figure 1: The number of 17 year-olds in England and Wales from 1985 to 2001. Source: DfES (2002a)

\section{The Demography of the 14-19 Age Cohort}

Any time series analysis of participation and achievement in the English Education and Training System needs to take account of the changing numbers of 14 to 19 yearolds. As Figure 1 indicates, the number of 17 year-olds (chosen as a reference group) has declined since 1985, reaching a low point of 537000 in 1995, then increasing somewhat to 610000 by 2001. This represents a decline of $32 \%$ between 1985 and 1995 , and of $23 \%$ in the time period overall. ${ }^{2}$

\footnotetext{
2 The figures here are based upon actuarial data and will be modified in light of census data.
} 


\begin{tabular}{|c|c|c|c|}
\hline $\begin{array}{l}\text { Level of } \\
\text { Qualification }\end{array}$ & General & Vocationally- Related & $\begin{array}{l}\text { Occupationally } \\
\text { Related }\end{array}$ \\
\hline 5 & \multicolumn{2}{|c|}{$\begin{array}{l}\text { Higher Level Qualifications, e.g. degrees } \\
\text { and post-graduate qualifications }\end{array}$} & Level 5 NVQ \\
\hline 4 & & & Level 4 NVQ \\
\hline $\begin{array}{l}3 \\
\text { Advanced } \\
\text { Level }\end{array}$ & GCE A Level & $\begin{array}{l}\text { VCE A Level } \\
\text { (Advanced GNVQ) }\end{array}$ & Level 3 NVQ \\
\hline $\begin{array}{l}2 \text { Intermediate } \\
\text { Level }\end{array}$ & GCSE A* - C & Intermediate GNVQ & Level 2 NVQ \\
\hline $\begin{array}{l}1 \\
\text { Foundation } \\
\text { Level }\end{array}$ & GCSE D - G & Foundation GNVQ & Level 1 NVQ \\
\hline Entry Level & \multicolumn{3}{|c|}{ Certificate of Educational Achievement } \\
\hline
\end{tabular}

Table 1: Locating major qualifications within the National Qualifications Framework (QCA, 2000)

Raffe et al. (1998: 2 - 3) point out that

'It was widely predicted that this significant decline in youth labour supply would significantly distort employer recruitment patterns - the so-called demographic timebomb. It was predicted that the shortage of youth labour would drive up earnings in the youth labour market, thus reducing education and training participation. This predicted trend failed to materialise.'

The failure of the 'demographic timebomb to explode' was partly due to a rapid increase in participation in post-compulsory education and training amongst 16 to 19 year-olds. This change in the pattern of choice amongst 15 and 16 year-olds seems, at least in part, to have been fuelled by changing levels of attainment in GCSE exams taken by young people at the end of compulsory schooling in England, combined with wider social changes (see Raffe and Sturridge, 1995).

\section{The English Qualification System}

The English qualification system is both complex and subject to continual and rapid change. Nonetheless, all qualifications are being accommodated within a National Qualifications Framework (Table 1) on the basis of their level and their location within one of three more or less distinct pathways. For the purposes of this analysis we focus on qualifications located at Levels 2 and 3 in the National Qualifications 
Framework. We also adopt the tripartite division of qualifications provided by the NQF to explore participation and attainment in the education and training system.

\subsection{The Last Two Years of Compulsory Education}

In theory, all young people in the UK are required to stay at school until the age of 16. In England, the main examination taken by students at the minimum school leaving age is the General Certificate of Secondary Education (GCSE). This is awarded at eight grades from $A^{*}-$ G. Typically, students will take eight or more GCSE examinations. Achieving five or more GCSE passes at Grades A* - C is deemed equivalent to achieving a Level 2 qualification, while achieving five GCSE passes at Grades D - G equates to a Level 1 qualification. In addition, students may also take vocationally related courses such as the Intermediate General National Vocational Qualification (GNVQ) or the Foundation GNVQ. A pass in the intermediate GNVQ is equivalent to four GCSE passes at grades $A^{*}-C$, while a pass in the Foundation GNVQ equates to four GCSE passes at Grades D - G. Thus, a student could be considered to have achieved a Level 2 qualification by either passing five separate GCSEs at grades $A^{*}-\mathrm{C}$, or a pass in an Intermediate GNVQ plus one GCSE pass at Grade $A^{*}$ - C. Notwithstanding the vocationally-related alternatives, the main emphasis in the last two years of compulsory education in England is currently still on general education.

Starting from a low level of attainment in comparison with other OECD nations, there has been a steady increase in the proportion of English students achieving a Level 2 qualification at the end of compulsory schooling from $32.8 \%$ in 1989 to $51.2 \%$ by 2002. The rise has been particularly pronounced for young women - from $35.8 \%$ to $55.6 \%$ - compared to young men - from $29.8 \%$ to $46 \%$.

The change in proportion of students achieving a Level 2 qualification by the age of 16 also translates into a steady increase in the total number of young people achieving this level. In 1990, approximately 220,800 young people obtained a Level 2 qualification at the end of compulsory schooling. By 2002, this number had grown to approximately 310,700, an increase of 54\%. This means that between 1990 and 2002, 
approximately 3.24 million young people achieved a Level 2 qualification by the end of compulsory schooling.

However, whilst the proportion not achieving any qualifications by the end of compulsory schooling had declined to $5.4 \%$ by 2002 , and the percentage achieving at least five passes at grades $A^{*}-G$ at GCSE/GNVQ equivalent had increased to $88.9 \%$, approximately $50 \%$ of all young people are not reaching the Level 2 standard at the end of compulsory schooling. The significance of this statistic lies in the fact that the greatest predictor of continuing and being successful with education post-16 is whether one achieves the Level 2 standard by the end of compulsory schooling.

\section{Participation from 16 to 19}

At the end of compulsory schooling, young people have to make a choice about the education and training pathway they wish to follow and, in the case of full-time courses, the institutions in which they wish to study. Essentially, there are four choices available to young people at this stage:

- full-time education which includes both the academic/general and vocationally-related pathways described earlier in either a school sixth-form or a college

- government sponsored training which falls into the third, occupational route and involves both employers and private training providers

- employment (either full- or part-time) with or without employer-funded training

- unemployment without benefits, i.e. status zero, with the New Deal for Young People presenting a reintegration route.

Figure 2 shows the changing patterns of participation for 16, 17 and 18 year-olds as depicted in administrative data, while Table 2 shows the main activity of young people in their first three years following compulsory schooling as revealed by the Youth Cohort Studies (YCS). Slight differences in definitions and procedures for 


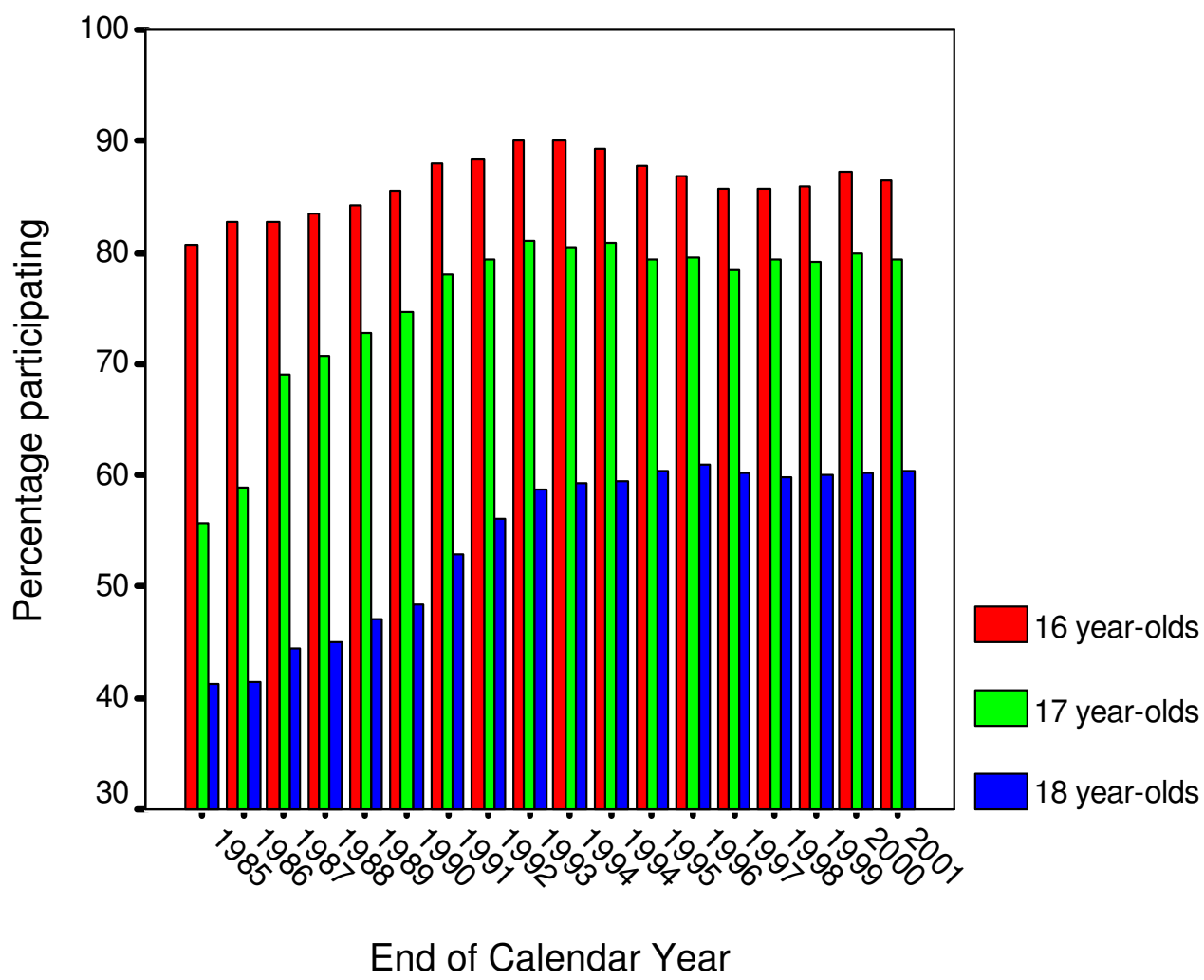

collecting the data produce somewhat different estimates in the two data sets. However, both tell broadly the same story: an increase in participation in all age groups up until the early 1990s, followed by a slow fall and then a more recent rise. In 2000, the last year for which verified administrative data are currently available, approximately $87 \%$ of 16 year-olds, $79.3 \%$ of 17 year-olds and $60.4 \%$ of 18 year-olds were in some form of education and training. Taken together, some $75.4 \%$ of 16 to 18 year-olds were in some form of education and training in 2000.

As Figure 3 indicates, the major factor underpinning this increasing participation rate is the increased participation in Full-Time Education (FTE) in both the general and vocationally related routes. Participation in these routes by 16 year-olds increased from $47.3 \%$ in 1985 to $72.6 \%$ in 1993 , followed by a slow decline to $69.4 \%$ in 1997 . Participation in FTE then started to increase again reaching $71.4 \%$ amongst 16 yearolds in 2000. 


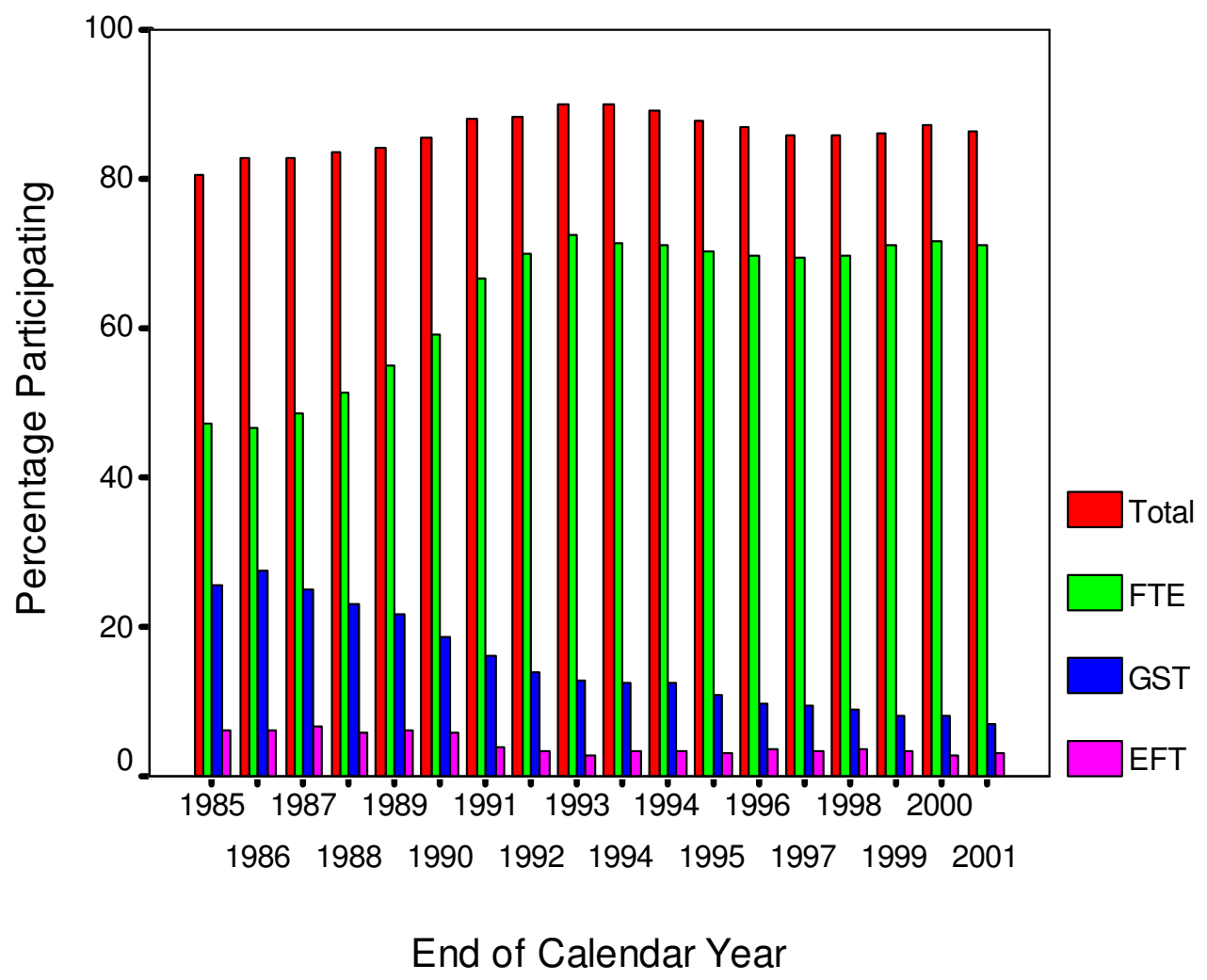

Government-Supported Training (GST), which includes Modern Apprenticeships, Life Skills and other training for young people, is the main component of the third pathway that young people can follow after the end of compulsory schooling. GST for 16 year-olds reached a peak in the second half of the 1980s with just over a quarter of 16 year-olds and a fifth of 17 year-olds participating. Participation amongst 16 yearolds has declined rapidly since then, reaching $8 \%$ in 2000 . The decline has been less rapid for 17 year-olds, with approximately $11 \%$ participating in GST in 2000. The same pattern is also true for those undertaking Employer-Funded Training (EFT).

Data from the Spring 2002 sweep of the Youth Cohort Study (DfES, 2003a,b) provides the most recent information on participation. This study indicates that $71 \%$ of 16 year-olds were in full-time education and 9\% were in Government Supported Training, values that are very close to the official estimates of $71 \%$ and $7 \%$ participation in FTE and GST respectively. The YCS indicates that $40 \%$ of 18 year- 
olds were still in FTE in Spring 2002 (official estimate 37\%) with a further 8\% in GST (official estimate 8\%).

The Youth Cohort Study data (Table 2), also demonstrates that the proportion of 16 18 year-olds in employment (excluding those involved in GST) has also declined over time. As Raffe et al. (1998) point out, this trend partly reflects the economic cycle, with a boom in the late 1980s being followed by a recession in the early 1990s. However, the economic growth of the mid- to late 1990s does not seem to have reversed the trend.

Raising participation rates in post-compulsory education in either the FTE or GST pathways is only the first step to meeting the political desire to increase the supply of qualified young people entering the labour market. Young people also have to stay in the system and to achieve qualifications.

\subsection{Retention and Survival Rates}

Compared to 1995, school expectancy in the UK (the expected years of schooling under current conditions) had increased by 10\% (OECD, 2002). However, as Figure 2 indicates participation in education and training in England and Wales falls in a steplike manner, so that participation at 18 still remains below the levels found in many other OECD countries. As the OECD (2002:9) points out,

'Drop-out and survival rates provide some indication of the internal efficiency of education systems. Students leave educational programmes before their completion for many reasons - they realise that they have chosen the wrong subject or educational programme, they fail to meet the standards set by their educational institution, or they want to work before completing the programme. Nevertheless, high dropout rates indicate that the education system is not meeting the needs of clients. Students may find the educational programmes do not meet their expectations or their needs in order to enter the labour market, or that the programmes require more time outside the labour market than they can justify.'

In terms of current UK education and training policy, premature exit from the education and training system is thought to be undesirable, though whether the pattern observed in Figure 2 can be equated with 'drop-out' is debatable. Young people may 
be leaving at the end of one-year vocational programmes, such as Intermediate GNVQ, to take up employment.

At the time when post-16 participation was increasing rapidly $(1985$ - 1992) the difference between the percentage of young people participating at 16 and 17 was approximately 16 per cent. Since 1992, this figure has decreased to 12 per cent. The cross sectional evidence suggests, therefore, that retention rates have improved over time. Evidence from the Youth Cohort Survey (DfES, 2003 a,b), a longitudinal study, supports this view. Furthermore, the YCS suggests that the majority of young people are in the same activity at 17 and 18 as they were in at 16 . For example, for those aged 16 in 1998/9, 86\% of those in full-time education at 16 were still in full-time education at 17. This trend persists for 18 year-olds though a greater proportion of the young people surveyed changed activities between 17 and 18 than between 16 and 17. For those changing activities, a job was the most common destination.

Retention rates also vary between the types of courses young people follow. Thus retention rates are much higher on two-year Level 3 courses for young people who have been academically successful at the end of compulsory schooling compared to those taking one-year Level 2 courses, such as Intermediate GNVQ, post-16. For example, Huddleston (2002) reports that in the academic year ending in July 1999, nationally only 60 per cent of students who registered on Intermediate Business GNVQ courses passed the course. The figure for the Intermediate GNVQ in Leisure and Tourism in the same year is 56 per cent. Furthermore, amongst the admittedly small sample of 140 students studied by Huddleston (2002) in four Further Education colleges, only 53 per cent of Intermediate GNVQ Business students and 46 per cent of students on Intermediate GNVQ Leisure and Tourism courses, remained on the programme until the end of the academic year. Not only do such courses have lower internal efficiency than two-year Level 3 courses, they also have essentially zero rates of return in the Labour Market (see below). 


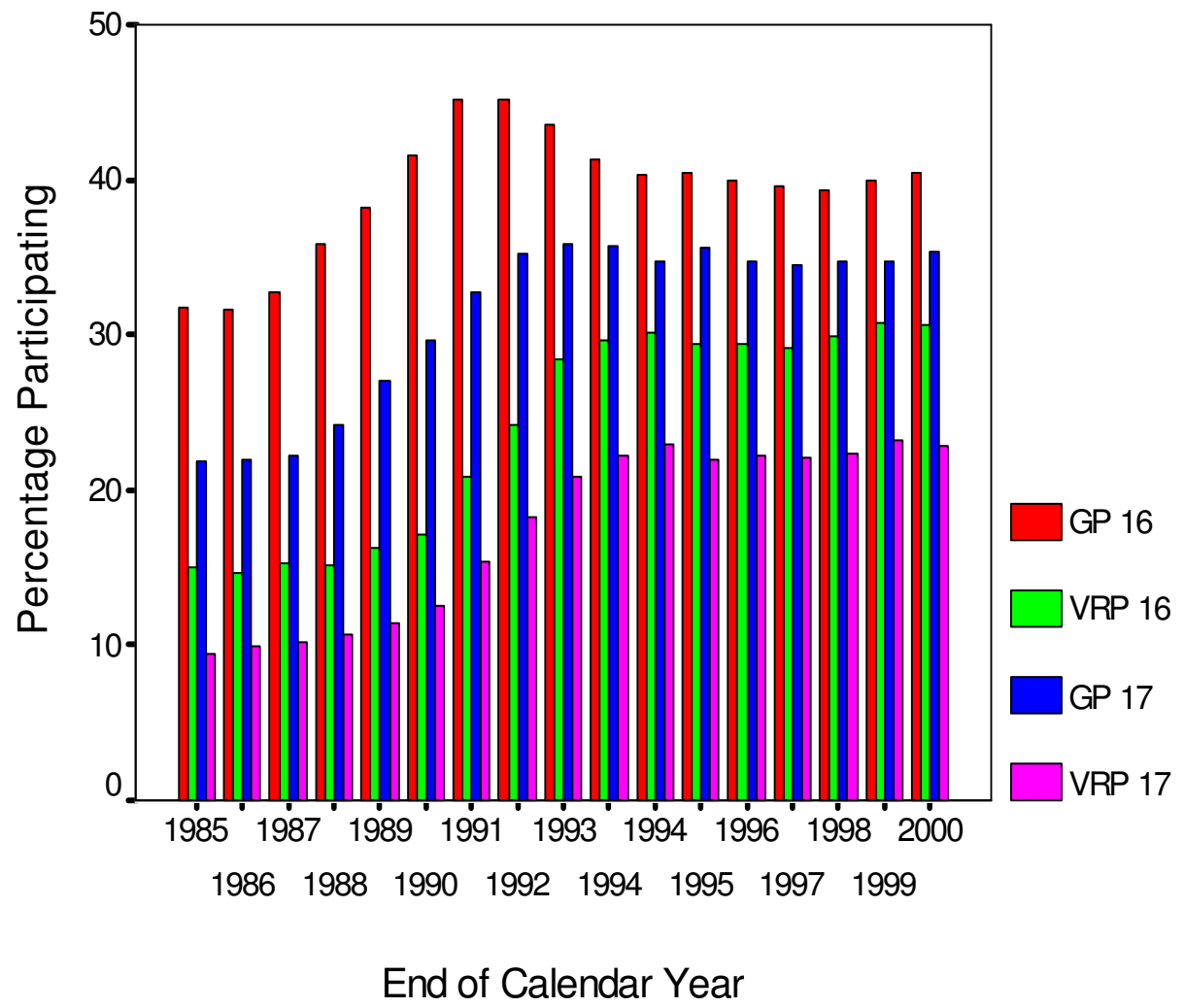

Figure 4: The percentage of 16 and 17 year-olds in full-time education participating in either the General Pathway (GP) or the Vocationally-Related Pathway (VRP). See previous text for further description of these two pathways. Source DfES (2002a)

\section{The qualifications mix}

The final stage of this audit is to examine the choices made by 16-19 year olds who are studying full-time. Those involved in Full Time Education from 16 to 19 are participating in two main pathways - the general and the vocationally-related - at a number of different levels. If we take GCE A Level and GCSE to constitute the general route and VCE A level/GNVQ/NVQ to constitute the vocationally-related route, then Figure 4 shows the changing pattern of participation in these two pathways over time.

Clearly, there has been an increase in participation in both the general and the vocational pathways. However, participation in the general pathway always exceeds participation in the vocationally related pathway. This reflects an underlying issue in the English education and training system compared with other European countries such as Germany, Austria, Denmark and Switzerland: lower participation in the vocational route. Furthermore, the growth in participation in the vocational pathway 


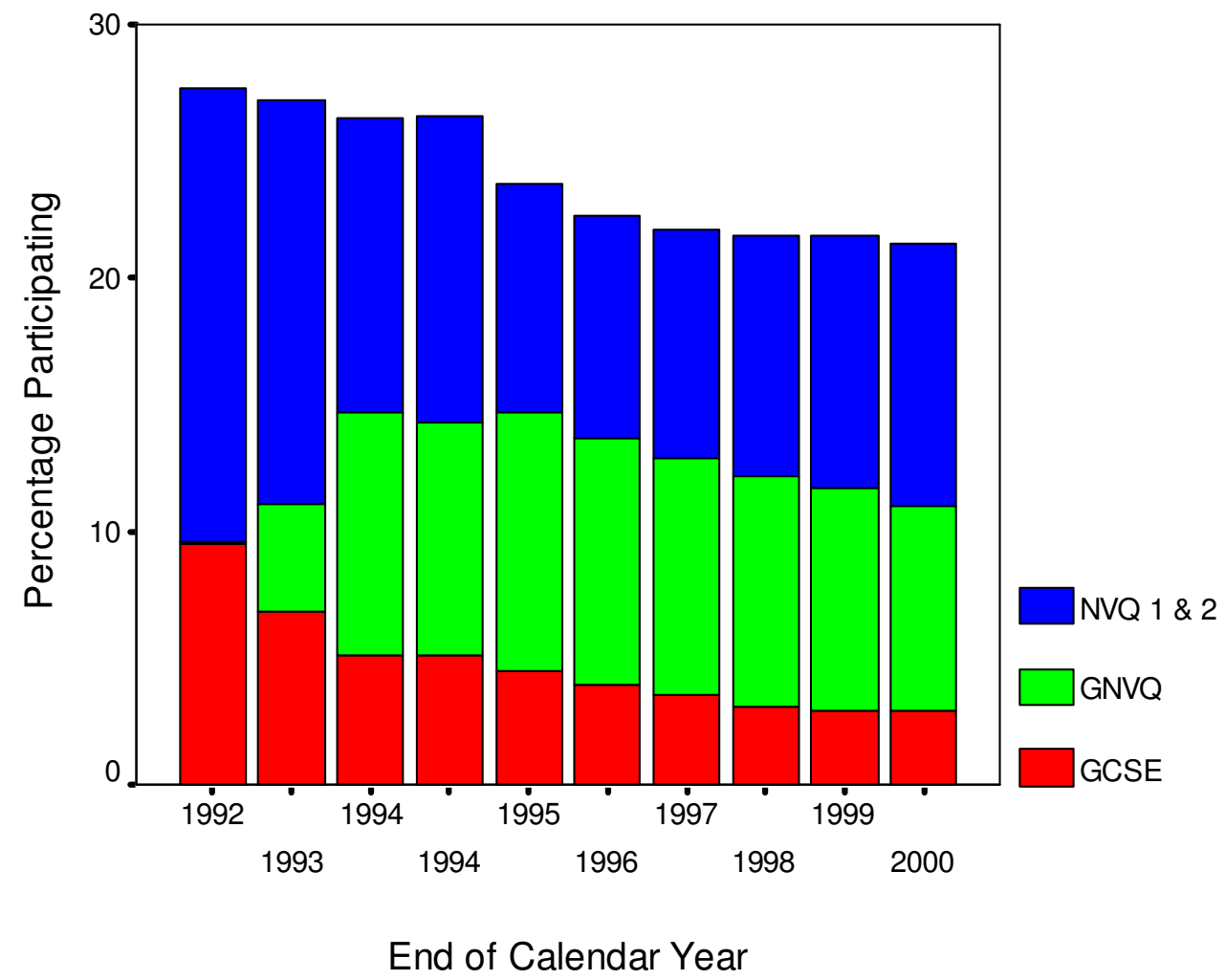

for 16 year-olds that can be seen in Figure 4 is almost wholly due to substitution effects: rather than retaking GCSEs, Figure 5 shows that 16 year-olds began to take Intermediate and Foundation GNVQs following their introduction in 1992. Despite the provision of these alternative vocational courses, total participation in courses leading to Level 2 qualifications post-16 in FTE has fallen over time. This is probably due to the increasing percentage of young people gaining a Level 2 qualification at the end of compulsory schooling. They can then opt either to take a Level 3 qualification or to enter the labour market at the end of compulsory schooling, for example through the Government-Supported Training pathway on, for example, an Advanced Modern Apprenticeship (AMA). However, uptake of the AMA option by 16 year olds is not a particularly popular choice with 46 per cent of all people starting an AMA being over the age of 19 (Fuller and Unwin, 2003).

As Figure 6 indicates, the disparity between the general and the vocationally-related route becomes even greater if we examine qualifications at Level 3: GCE A levels, Advanced GNVQ/VCE A levels and NVQs at Level 3. In 2000, of 16 year-olds in England taking full-time Level 3 courses 76 per cent were taking GCE A/AS 


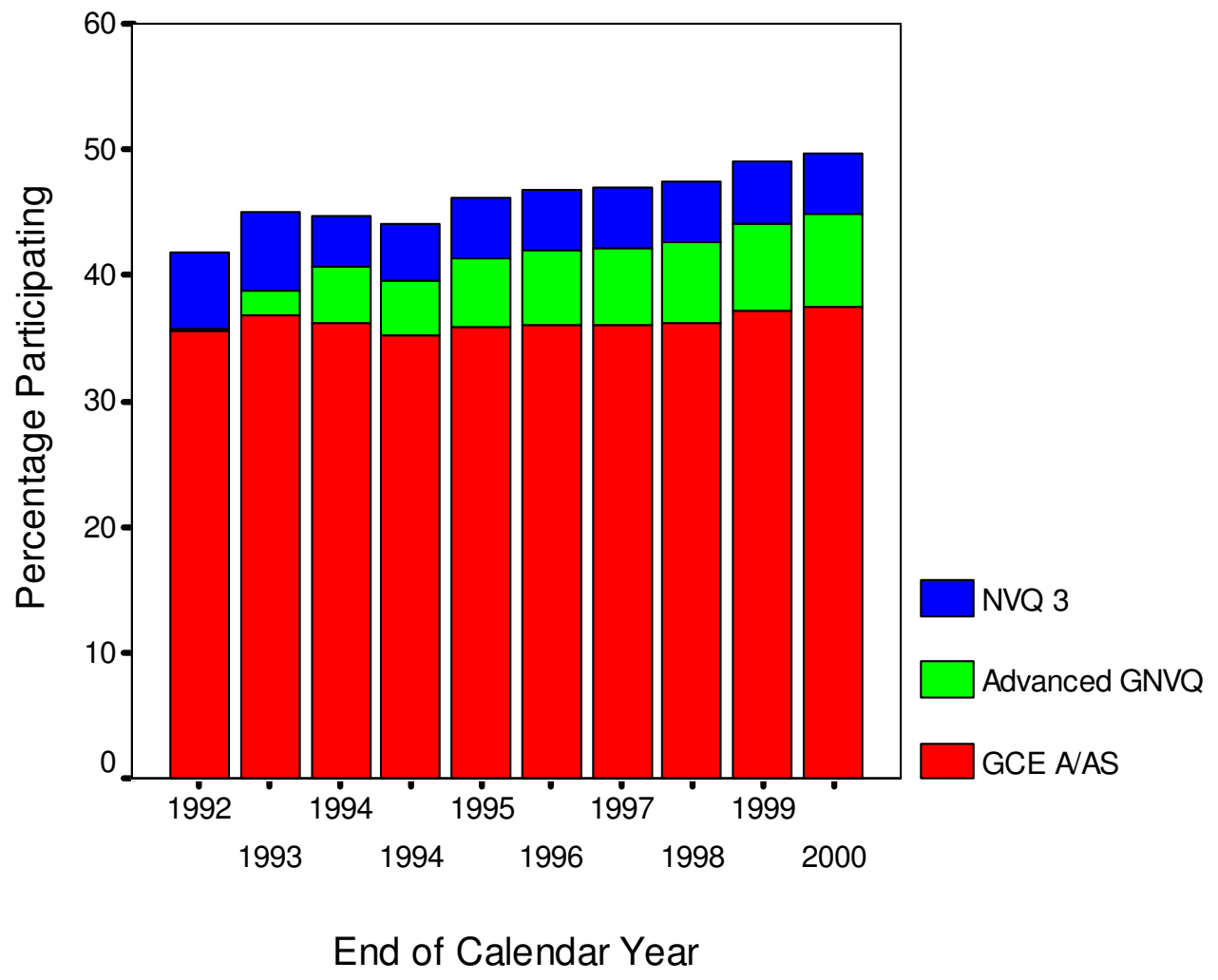

compared to 15 per cent taking the Advanced GNVQ/VCE A/AS option, and 10 pre cent taking the NVQ Level 3 or other equivalents. In other words, at Level 3, three times as many English 16 year-olds in full-time education were taking GCE A-levels than were taking either GNVQs/VCE or NVQ Level 3.

The evidence presented so far shows an increasing proportion of 16 - 19 year olds participating in post-compulsory education, particularly in general full-time education. Furthermore there seems to be some slightly higher retention and accomplishment rates within the English education and training system. Overall it appears that the sequence of policies implemented, most likely aided by factors external to them, have been successful in increasing the proportion of young people accessing and completing qualifications in the UK. However, simply counting the number of graduates or the number of qualifications achieved does not necessarily inform us about the quality of the education outcomes with respect to the demands of the economy for skills. It is to this that we now turn. 


\section{Qualifications and the Labour Market}

Although for an individual the acquisition of qualifications can be an end by itself, at the aggregate or country level and from an economic point of view, this decision is generally taken to be a means to an end. The economic case for supply side education policies follows the literature on economic growth that postulates that education plays a fundamental part in the process of economic growth (Temple, 2001; Sianesi and Van Reenen, 2002). On the basis of this evidence, supply side education policies aim at providing the appropriate environment for sustainable development. These theories rely on the assumption that the use of incoming skills in the labour market will boost productivity and ensure long-term economic growth. Therefore, the deployment of skills in the productive side of the economy, the demand side, is as important as their acquisition for the success of these policies. Within this framework, the use and value of education in the labour market appears to be a better means to assess supply side education policies aimed at guaranteeing economic growth. In the UK the situation is such that the labour market dictates the quantity and quality of skills at use or on demand, whereas the supply of skills is centralised through public sector policies. The interaction between the two sides of the market for skills may result in aggregate imbalances, indicating difficulties in the production of the right skill mix and therefore casting doubt on the success of supply side education policies. In what follows we analyse the prevailing equilibrium between qualifications supply and demand in the British labour market.

\subsection{Qualifications Demand and Supply in the UK}

The standard approach to identifying what skills are in high demand is to estimate the returns to education. Wages summarise the value that the labour market places on skills. Wage premiums on particular skills can be regarded as a signal that either those skills are in short supply or else that their contribution to the productive side of the economy out-weights the cost of obtaining them ${ }^{3}$. In any case, the interpretation of the

\footnotetext{
3 The estimation of returns to education through wages approximates the private returns to the individual person. It is beyond the scope of this paper to discuss whether the social returns would be higher due to positive externalities, Temple (2001), and Sianesi and Van Reenen (2002) consider this possibility.
} 
wage premium signal is that those skills are worthwhile investing in, hence justifying the use of the returns to education technique as a means to identify them.

There is a wealth of empirical evidence on the returns to qualifications by level of attainment, sometimes distinguishing between academic and vocational qualifications and by subject of degree ${ }^{4}$. The message from this literature is clear: acquiring qualifications pays off. Furthermore, the higher the level of qualification, the better the return compared to not having qualifications. The estimates of the returns to education vary themselves depending on the data set and the technique used to obtain them. Considering broad qualifications, the returns to obtaining O-Levels or GCSE qualifications (Level 2) pay some 8-20\% more than not having them. An additional $17-23 \%$ accrues to those acquiring two or more A-levels (Level 3). Lower vocational qualifications (up to and including Level 2) earn no return in the labour market compared to not having them while Level 3 Vocational Qualifications earn some 7$12 \%$ higher wages than those who do not have them (Dearden et al, 2000). More important than the existence of handsome dividends to acquiring qualifications is the fact that these returns do not show a clear tendency to decline in recent times (Walker and $\mathrm{Yu}, 2001$ ). Since rates of return to qualifications remain stable in the UK despite the increase in qualifications held by the labour force, the recent expansion of postcompulsory education, for example, does not seem to have resulted in an over-supply of qualifications.

Although conventionally accepted, the use of rates of returns to identify skills in high demand in the labour market is not a perfect technique. Wages are the result of the interaction between labour demand and supply, and therefore wage premiums could be capturing the effect of various characteristics of workers other than qualifications. The most cited example of this kind of problem is innate ability. More-able people are more likely to obtain qualifications. More-able people are also likely to be more productive and earn higher wages. Therefore, a positive correlation between qualifications and wages can be observed independently of the value of education itself. Most studies on returns to education acknowledge this possibility and different

\footnotetext{
${ }^{4}$ Dearden et al. (2000) and Walker and Yu (2001) contain literature reviews as well as recent evidence on the returns to education in the UK.
} 
techniques have been developed in order to reduce the noise that the wage signal contains as a measure of the value of qualifications (Blundell et al. 2002). The conventional method to remove the effect of variables other than education on wages is to include controls for them in the estimation of rates of return. The quantity and quality of controls depends on the data set but it is common to include individual characteristics such as gender, ability and family background, and firm characteristics such as size or sector. Nevertheless, the extent to which the wage signal is "clean" after controlling for other effects remains uncertain.

An alternative way of assessing the balance between the supply and demand of qualifications in the labour market is to look at the qualifications held by the labour force and compare them with those required for the jobs they hold. There is probably no objective way to disentangle the qualifications required to perform a particular job from those actually held by the jobholder, not least because in many cases jobs are shaped by the person who is performing them. One approach is to directly ask workers what qualifications they think would be needed in order to get the job they hold. This was the approach taken by Felstead et al (2002) for their report Skills in Britain 1986-2001. Taking the jobholder's judgement of qualifications requirements for that job as demand, and considering how many people there are in the labour force holding those qualifications, the authors come up with a sizeable excess supply of qualifications at Levels 2 and 3 (Figure 3.2, ibid). There seem to be many more people in the labour force holding these qualifications than available jobs that would require these qualifications. The excess supply exceeds 2 million people for Level 3 qualifications and it is of the order of 1.5 million for Level 2 qualifications. Considering trends, in Figure 4.2 the authors illustrate how this excess supply of qualifications held by the labour force arose as a result of widespread educational upgrading in the population. This emerging excess supply shows that education policies have indeed achieved their goal of raising the educational attainment of the labour force.

Objections can also be raised to the use of worker's perceptions as an approximation for the demand of qualifications (Hartog, 2000). Following from the fact that demand seems to be lower than supply it could be argued that workers perceive their jobs as 
less demanding due to experience, for example. The extent to which workers reported a required qualification below the one they held gives an idea of the importance of this criticism. Between 40 and 50\% of workers holding qualifications at both Levels 2 and 3 regarded themselves as over-qualified (Table 4.6, ibid). The incidence of perceived over-qualification appears to have increased for workers who hold Level 2 qualifications but no clear trend was observed for workers with Level 3 qualifications.

\subsection{Reconciling the Evidence}

Leaving aside problems with measurement and estimation techniques, the conflicting evidence provided by these two approaches has important implications for labour market performance. On the one hand, the evidence based on returns to qualifications suggests there is a wage premium for obtaining some of them. On the other hand, the evidence on the actual requirements in the labour market suggests there is an excess supply of them. There are at least two economic scenarios where both these observations could coexist.

One possibility is a case of over-qualification in the labour market. Over-qualification arises in the presence of an excess supply of qualifications. Workers can be thought of as being picked from a queue where the more qualified workers are first. Since there are more workers than jobs, workers with higher qualifications will end up in jobs for which only lower qualifications are required. These workers will be over-qualified but they will still earn more than the average worker with the appropriate level of qualifications for the job. Thus, some positive return to qualifications will be obtained even if there is an excess supply of qualifications. Indeed, Groot et al. (2000) present evidence of positive returns to over-education ${ }^{5}$. The evidence suggests that overqualified workers earn less than workers with the same qualifications in jobs for which their level is required, but they earn more than workers with the appropriate level of qualifications in jobs for which lower qualifications are required.

\footnotetext{
${ }^{5}$ Over-education and over-qualification are identical concepts in this paper. The term over-education appears to be associated "too much education", an implication that we would like to avoid by using the term over-qualification.
} 
The question remains, however, whether the rising incidence of over-qualification in the UK means that there are too many qualifications in the labour market (Green and McIntosh, 2000). Since there are some positive returns to over-qualification (see Appendix), the labour market seems to be attaching some value to qualifications even though they are not required for the job. Over-qualification can also be the result of some failure in the allocation of workers to jobs through the labour market. The wrong match of worker-job qualification could be due to lack of adequate information about one or the other part of the pair. The presence of under-qualification lends support to this argument since it is incompatible with the idea that there are too many qualifications and workers compete for the jobs that require their possessed qualifications. The incidence of under-qualification is much lower than that of overqualification though (Table 4.6 in Felstead et al, 2002). Furthermore, underqualification appears to be declining over time, whereas over-qualification is on the rise, hence suggesting that over time there could a stronger case for the excess supply hypothesis than for the information asymmetry story.

An excess supply of qualifications could also concur with positive returns to education if qualifications were being used for signalling productivity when employers cannot observe the worker's productivity ${ }^{6}$. Upon recruitment employers are normally unable to separate candidates between the better or more productive and the less productive ones. More-productive workers are willing to indicate their value to the employer so that they get the job and the higher wage. Education or qualifications can be used for this purpose provided that the cost of acquiring education is lower for the better workers (Spence, 1973, 1979). Better candidates will signal their value through their qualifications while employers will use the signal to select candidates and offer them higher wages. If this were the case, and education were made available to an increasing number of people at lower cost, every worker would sensibly try to reap of some of these benefits. Over time the signalling value of education will be reduced as an increasing proportion of the labour force acquire qualifications independently of their potential productivity. Some, probably lower, returns to qualifications could still remain provided that better workers continue to obtain qualifications and they unveil their higher productivity through some 
alternative means. As stated earlier, however, there does not seem to be a clear declining trend in the returns to qualifications in the British labour market. Hence, either education is not used as a signal or the expansion of post-compulsory education has not reduced significantly the average quality of graduates.

\subsection{An Alternative Approach to Skills Demand}

There remains a third approach to analyse the extent of skill mismatch in the labour market and that is directly asking employers about their needs. Unfortunately it does not seem to be common to ask employers about required qualifications for the posts they have. Understandably though, and particularly in bigger firms, employers could be unaware of the particular needs of every single job in the firm. The Employers Skill Survey in the UK (ESS henceforth) tends to ask employers about recruitment difficulties and skills deficiencies of their workforce so that the comparison with qualifications demand and supply is limited. They are asked, however, whether lack of qualifications is a cause of hard-to-fill and skill-shortage vacancies, although this reason is not one of the most important ones causing vacancies (Frogner, 2002).

Recent educational policies and particularly the introduction of Key Skills as part of the school/college curriculum seem to have followed findings from the ESS. The evidence provided by the Survey suggests that apart from "technical skills", and "company/job specific skills", skills most sought after are generic skills like IT, communication, customer-handling and team-working skills (Fig. 2.8 in ESS). Furthermore the findings also suggest that the most important reason for the presence of recruitment difficulties is the "Low number of applicants with skills" followed by "Low number of applicants in general" and "Lack of work experience" (ESS Fig 2.9). Lack of work experience and the need of job specific skills are not easy to deal with through external interventions. By including the sought after skills in the school/college curriculum, however, the problem of the lack of applicants with the right skills could be tackled provided that the skills are effectively acquired through formal education and are transferable from educational to work contexts.

\footnotetext{
${ }^{6}$ The signalling model can also explain the positive returns to over-qualification found in the literature.

7 "Technical Skills" refer to advanced IT/software skills and other technical/practical skills. See table 2.20 of Employers Skills Survey.
} 
One of the innovations of the last 16-19 educational reform in the UK, Curriculum 2000 was to include Key Skills ${ }^{8}$ as part of the curriculum. This intervention provides us with a unique natural experiment to assess whether generic skills can be successfully provided within the formal education system.

The immediate effect of providing the opportunity to acquire these units in the post-16 curriculum is to transform Key Skills into a qualification, which takes us back to our initial discussion on the market for qualifications. As explained before, to the extent that education is an investment, the perceived rewards to Key Skills become one of the main determinants of their acquisition in the formal education system. Following from the ESS, increasing wages is not the most likely response of employers to the problem of skill-shortages and hard-to-fill vacancies (Frogner, 2002). It is too early to obtain evidence on the returns to these qualifications but even if Key Skills qualifications had a positive return in the labour market, students face a trade-off between investing their time in taking these qualifications or other ones, such as additional AS levels. If further education is being considered by the student then the value that Higher Education institutions put on Key Skills becomes relevant for the choice.

Two forces are at work when analysing the outcomes of this intervention. On the one hand colleges and schools have to make the new 'subjects' available with limited guidelines about their contents and with limited financial aid for the provision of Key Skill qualifications. On the other hand and once Key Skills units are on supply students have to decide or be attracted into taking these qualifications rather than some alternative qualification. At the time of writing administrative data about the uptake of Key Skills were not available. However, the Universities and Colleges Admission Service (UCAS) undertook a series of surveys to investigate the implementation of Curriculum 2000 that does provide data on the uptake of Key Skills.

\footnotetext{
${ }^{8}$ There are six Key Skills offered al Levels 1 to 4: Communication, IT, Application of Number, Working with Others, Improving Own Learning and Performance, and Problem Solving.
} 
In the survey of November 2001 (UCAS 2002a), approximately 15 months after the implementation of the Curriculum 2000 reforms, only 44 per cent of the institutions that responded reported offering Key Skill qualifications to their second year students taking Level 3 courses. The percentage was highest for Sixth Form (80 per cent) and FE (74 per cent) colleges but much lower in Comprehensive (51 per cent), Grammar (29 per cent) and Independent (25 per cent) schools. Responses to the survey suggested that only 38 per cent of second year students were working towards one or more Key Skill qualifications with 14 per cent of learners being entered for one, 6 per cent for two and 15 per cent for three Key Skill qualifications. Amongst the six Key Skills, entry for certification was highest amongst the so-called 'hard' Key Skills of Communication (26 per cent), Information Technology (24 per cent) and Application of Number (17 per cent). Entry for the three 'wider' Key Skills was negligible: Improving Own Learning and Performance (1 per cent); Working with Others ( 0.7 per cent) and Problem Solving (0.5 per cent).

The explanation of this poor uptake resides in the cost and benefits of providing/taking these qualifications and their perceived rate of return to both students and educational institutions. Both institutions and students suffered high costs associated with the increased assessment and teaching burden represented by the Key Skills qualifications. These costs were both direct, in terms of entry fees for Key Skills qualifications, and indirect in the form of substantial opportunity costs. Given that students enrolled on two year Level 3 courses are typically aiming for entry into Higher Education as the primary outcome of the 16-19 phase of education, the apparent lack of benefits of the Key Skills qualifications for Higher Education entry purposes is a strong disincentive to take the qualifications rather than, say, an additional AS subject.

'The lack of interest in the Key Skills in many quarters of higher education remains a problem since this discourages both teachers and students and makes it difficult to devise and explain a clear and coherent national policy on the key skills. In light of this ... it will be necessary to continue to emphasise the importance of students developing their key skills particularly in the context of the development of the 14-19 phase.' (QCA, 2001:4) 
The huge scale of the lack of interest in Key Skills as entry qualifications for Higher Education is borne out by an analysis of the provisional offers made to a random sample of 5473 students applying through UCAS in 2002 for 2003 entry to Higher Education. 'Key skills were specifically included in only a small minority of [offers] (6.1\% of offers made by Post-92 universities, $4.5 \%$ of offers made by HE colleges, $3.8 \%$ of FE colleges and $0 \%$ of Pre-92 universities)' (UCAS 2002b:19). This antipathy to Key Skills on the part of Higher Education admissions tutors also extends to students who were reported to have 'a negative attitude towards key skills, and are only doing the qualification because it attracts UCAS points 9 ' (QCA, 2001: 6).

To overcome this weak uptake, the current policy on Key Skills is based both on inducements, particularly the provision of funds for participation in Key Skills programmes even if they do not lead to assessment and certification, and the revision of the testing regime to make it less of a burden. However, the view that moving 'as swiftly as possible to a system of on-demand and, eventually, on-line testing holds the key to the future success of these qualifications' (QCA, 2001: 3) seems to fly in the face of the evidence that they key to making these qualifications more attractive to learners is to convince $\mathrm{HE}$ admissions tutors of their worth, at least for those studying at Level 3. The chances of a weak hortatory policy instrument (Schneider and Ingram, 1997), which continues 'to emphasise the importance of students developing their Key Skills particularly in the context of the development of the 14-19 phase' (QCA, 2001:4), overcoming the apparent rejection of Key Skills qualifications by both learners and their teachers seem slim within the current incentive structure. The lack of clear-cut returns to Key Skills qualifications and in the presence of a trade-off between these and other qualifications, the introduction of Key Skills as part of the post-compulsory curriculum offer is unlikely to achieve the goal of reducing skillsshortages in the labour market.

\section{Whither 14-19 Education and Training Policy?}

In this concluding section we consider some important messages that the above analysis might have for current suggestions for yet another round of $14-19$

\footnotetext{
${ }^{9}$ UCAS Tariff points can be used for admission to Higher Education.
} 
Education and Training Reform. The English Education and training system has been subject to a series of reforms over the last two decades that have aimed to increase the supply of qualifications into the labour market. Some of these reforms, for example the introduction of the GCSE examination, appear to have been successful and others, for example the increased focus on developing basic literacy and numeracy skills in primary schools, were undoubtedly necessary. Others, for example the Curriculum 2000 reforms, have been at best neutral in their effect and at worst a costly diversion. Yet the evidence from recent 14-19 policy documents suggest that Policy makers are still wedded to the idea of qualification led education and training reform.

Clearly, a greater proportion of 16 - 18 year-olds are now choosing to remain in FullTime Education, and so delay their entry into the labour market for longer. These data indicate that the trend described by Bynner and Roberts (1991) in the early 1990s, that young people in England and Wales were making longer and later transitions to employment, has continued though the major phase of growth in participation in the 16-19 education system took place in the late 1980s and the early 1990s. Subsequently, a new equilibrium appears to have been reached in terms of participation, retention and certification rates.

Labour market returns to academic qualifications (GCSE and GCE A level) and Level 3 vocational qualifications remain positive. However, returns to lower level vocational qualifications appear to be zero. This suggests that employers still place a premium on academic and higher level qualifications. Furthermore, this labour-market advantage seems to be retained even in circumstances of over supply of qualifications. Consequently, efforts to enable more young people to attain higher level qualifications seem justified. The challenge is how to do this given the deplorable tail of under achievement in the English education system at the end of compulsory schooling.

The major impetus for growth in participation amongst sixteen years in education and training after the end of compulsory schooling was increasing participation in FullTime Education (FTE). It is impossible to say whether the increase in participation in post-compulsory FTE during the late 1980s and the early 1990s was attributable to 
government policy. Raffe and Sturridge (1995) argue that rather than invoking the development of a 'learning culture' in English society to explain these changes, we should seek to understand increases in participation in terms of incentive structures. These are constituted by factors which act both to promote participation at both national and local levels and to dissuade young people from either participating in the first place or, having been recruited, to then leave the education and training system.

Several factors are hypothesised to have led to increased participation (Raffe and Sturridge, 1995):

- compositional changes: more young people have characteristics (such as middle-class backgrounds and high GCSE attainments) which are associated with a propensity to stay on.

- 'push' factors from school and home: reforms in compulsory education, notably the introduction of GCSEs encouraged more positive attitudes to learning and encouraged young people to stay on.

- marketing of post-compulsory opportunities: the marketisation of education in England and Wales meant that schools and colleges had to compete more actively for post-16 students at a time when the 16-19 cohort was declining in size.

- $\quad$ 'pull' factors from the labour market: in the past, the high wages and highstatus occupations available to many 16 year-old leavers provided strong incentives to leave early; occupational changes and the relative decline in youth wages have reduced these incentives. Conversely, the labour market increasingly demands higher qualifications to enter employment (even if they are not required to do the job) which can be obtained by staying on.

- 'pull' factors from higher education: the demand for higher education responds to supply. When HE was allowed to expand after 1987, more people stayed on in post-16 education to prepare for HE entry.

Given this set of factors what should public policy makers do to increase further the supply of qualified young people into the labour force? The evidence from the Youth Cohort Studies suggests that once young people opt into the full-time education 
system at 16 , they tend to stay until the age of at least 18. Consequently, the decision to 'stay on' is crucial and here there seems to be a strong link with examination performance at the end of compulsory schooling.

'Participation in full-time education at 18 is strongly linked to performance in year 11. Less than a fifth of those with no GCSE grade $A^{*}-\mathrm{C}$ in year 11 were in full-time education at 18, whereas almost three fifths of those gaining five or more grades $\mathrm{A}^{*}-\mathrm{C}$ were in full-time education. However, within this latter group, those obtaining eight or more grades $A^{*}-C$ were more than twice as likely as those gaining $5-7$ grades $A^{*}-\mathrm{C}$ to be in higher education' (DfES, 2003b: 2).

This suggests that, unsurprisingly, raising attainment at the end of Key Stage 4 is likely to be one of the most powerful determinants of raising participation and attainment post-16. The causes of poor examination performance at the end of compulsory schooling are clearly complex but there are strong associations with social class, parental occupation, gender and, to some extent, ethnicity. In part the explanation for poor performance in exams at the end of compulsory schooling maybe that some young people are simply not ready for the assessment because they have not had sufficient time to develop the level of skills necessary to gain the grades in GCSE exams needed for a Level 2 qualification at the end of compulsory schooling (Huddleston, 2002). Thus, investing more money in primary schools and the early years of secondary education to ensure that more young people master functional literacy and numeracy skills, for example, may be the best approach to increasing later participation and retention in the post-compulsory education and training system, rather than yet another wholesale reform of 14-19 education and training.

Despite all of the political and economic capital invested in improving the supply of qualifications into the UK economy, employers are still disgruntled. Young people do not, according to employer surveys, have the right kind of skills, and therefore there exists a possibility of a mismatch between the skills embodied in qualifications and the skills needed in the workplace. Given this, the increasing policy emphasis being placed upon educational investment as a source of economic growth has led to a growing debate about the type of investment in education and training that the state, learners and their families should be expected to make. In particular there is a 
continuing policy emphasis on improving participation in the vocational route and on ensuring that young people acquire Key Skills.

However, learners at Level 3 seem to be rejecting both the opportunity to learn in the vocational route and the work-based Modern Apprenticeship route, and we hypothesise that this is due to the incentives offered for studying in the general route within the English education system. The behaviour of learners and their families in choosing the general route is consistent with them having absorbed the messages about the higher rates of personal return accruing to higher levels of qualification gained through the general route. The current importance of this to parents can be gleaned from the results of the focus group interviews conducted for the Sir John Cassell's report on Modern Apprenticeship. Many parents, whilst expressing their approval of the revised form and structure of the Modern Apprenticeship, still saw their children's future as lying within the full-time education pathway, particularly in the A level route, as this still represented the highway to Higher Education and kept their children's options open for longer. However much such a calculus has a distorting or undesirable effect from the perspective of policy makers, with too many learners choosing to opt for the traditionally more 'risky' GCE A level pathway rather than vocational or work-based routes, it is unlikely to be overturned by hortatory policy discourses promoting the parity of esteem of vocational and academic qualifications, or the importance of Key Skills in the labour market.

We think the time has now come to break away from our fixation on qualification led reform, on vain attempts to promote parity of esteem between vocational and academic pathways, and motivational technologies based on performance management, narrow accountability measures and National Education and Training Targets. More emphasis should be placed on the need to construct varied, meaningful and authentic experiences that meet the learning needs of all young people in the 1419 age-cohort. As Eraut (1997: 281) argues: 'The focus on qualifications rather than the development of knowledge and skill, motivation and learning, leaves too many assumptions unchallenged'. By focusing on desired learning outcomes we can take account of, for example, that rich tradition of socio-cultural research on knowledge and skill use in workplaces (Stasz, 2001) as a source of insights into how to build 
more effective learning opportunities for young people in school. Improved learning opportunities are needed if learning is to become addictive (Eraut, 1997:295) and if young people are to be motivated to carry on learning in later life. Getting learning right in the 14-19 phase will also lead to improvements in certification rates. Ultimately, educational institutions and supply side reform can only achieve so much and Tony Blair is wrong in his assumption that getting schooling right will lead to higher productivity and more equality on its own. The policy lens must shift from the supply side to the demand side. This means thinking harder about the ways in which, and the extent to which, public policy can be used to promote formal and informal learning in the workplace and the community, which has the largest part to play in making lifelong learning a real possibility. 


\section{References}

Blundell, R., Dearden L. and Sianesi B. (2002), Estimating the Returns to Education: Models, Methods and Results. CEE Discussion Paper \# 16

Dearden, L., McIntosh, S., Myck M., and Vignoles, A. (2001) The Returns to Academic, Vocational and Basic Skills in Britain. DfEE Research Report

DfEE (1998) Youth Cohort Study: The Activities and Experiences of 18 Year Olds: England and Wales 1996. London: DfEE

DfEE (1999a) Youth Cohort Study: The Activities and Experiences of 16 Year Olds: England and Wales 1998. London: DfEE

DfEE (1999b) Youth Cohort Study: The Activities and Experiences of 18 Year Olds: England and Wales 1999. London: DfEE

DfEE (2000) Statistics of Education: Vocational Qualifications in the United Kingdom 1998/99. London: DfEE

DfES (2001a) Youth Cohort Study: The Activities and Experiences of 16 Year Olds: England and Wales 2000. London: DfES

DfES (2001b) Youth Cohort Study: The Activities and Experiences of 18 Year Olds: England and Wales 2000. London: DfES

DfES (2001c) Youth Cohort Study: The Activities and Experiences of 21 Year Olds: England and Wales 2000. London: DfES

DfES (2001d) Youth Cohort Study: The Activities and Experiences of 17 Year Olds: England and Wales 2000. London: DfES

DfES (2001e) Youth Cohort Study: The Activities and Experiences of 19 Year Olds: England and Wales 2000. London: DfES

DfES (2002a) Statistics of Education: Education and training Statistics for the United Kingdom. London: DfES

DfES (2002b) Statistics of Education: Vocational Qualifications in the UK: 2000/01

DfES (2002c) GCSE/GNVQ Results for Young People in England, 2001/2. Early Statistics. London: DfES

DfES (2002d) Participation in Education and Training by 16 and 17 year olds in each local area in England, 1998 to 2000. http://www.dfes.gov.uk/statistics/DB/SBU/b0368/index.html 
DfES (2002e) GCSE/GNVQ and GCE A/AS/VCE/Advanced GNVQ Examination Results 2000/2001 - England.

http://www.dfes.gov.uk/statistics/DB/SBU/b0334/index.html

DfES (2002f) Annual Labour Force Survey.

http://www.dfes.gov/uk/statistics/DB/vol/0326/index.html

DfES (2003a) Youth Cohort Study: The Activities and Experiences of 16 Year Olds: England and Wales 2002. London: DfES

DfES (2003b) Youth Cohort Study: The Activities and Experiences of 16 Year Olds: England and Wales 2002. London: DfES

Eraut, M. (1997) Curriculum Frameworks and Assumptions in 14-19 Education. Research in Post-Compulsory Education, 2, 281 - 297.

Frogner, M. L. (2002) “Skills Shortages” Labour Market Trends, Jan 2002. London: DfES.

Hartog, J. (2000) "Over-education and earnings: where are we, where should we go? Economics of Education Review 19(2).

Hogarth T, Shury J, Vivian D, Wilson, R (2001), "Employers Skill Survey 2001: Statistical Report", DfES (ESS) accessed through www.skillsbase.dfes.gov.uk.

Huddleston, P. (2002) Uncertain Destinbies': Student Recruitment and Retyentyion on GNVQ Intermediate Programmes. SKOPE Research paper no. 37. Warwick: SKOPE

Keep, E. (2002) The English Vocational Education and Training Debate - Fragile 'Technologies' or Opening the 'Black Box': two competing visions of where we go next. Journal of Education and Work, 15 (4), pp. 457 - 479.

Keep, E. \& Mayhew, K. (1999) The Assessment: Knowledge, Skills and Competitiveness, Oxford Review of Economic Policy, 15 (1), pp. 1 - 15.

Lafer, G. (2002) The Job Training Charade. Ithaca: Cornell University Press.

Machin S., McIntosh S., Vignoles A. and Viitanen, T (2001). Basic Skills, Soft Skills and Labour Market Outcomes: Secondary Analysis of the Natinal Child Development Study. DfES Research Report 250.

Mincer, J (1974) Schooling, Experience and Earnings. New York: Columbia University Press.

OECD (2002) Education at a Glance. Paris: OECD.

PIU (2001). In demand: Adult skills in the $21^{\text {st }}$ Century. A Performance and Innovation Unit Report, Cabinet Office, December 2001.

QCA (2001) The Review of Key Skills: The Final Report. London: QCA. 
QCA (2003) The National Qualifications Framework. http://www.qca.org.uk/nq/framework/

Raffe, D., Biggart, A., Fairgrieve, J., Howieson, C., Rodger, J and Burniston, S. (1998) Thematic Review of the Transition from Initial Education to Working Life: United Kingdom Background Report. Paris: OECD.

Raffe, D. and Sturridge, P. (1995) More of the Same? Participation of 16 - 18 year olds in Education. National Commission on Education Briefing (new Series) 6.

Sianesi, B., and Van Reenen, J. (2002) The Returns to Education: A Review of the Empirical Macroeconomic Literature. IFS Working Paper 05/02

Spence, M. (1973) Job Market Signalling. Quarterly Journal of Economics 87, 355-

Stasz, C. (2001) Assessing skills for work: two perspectives. Oxford Economic Papers, 3, 385-405.

Temple, J. (2001) Growth Effects of Education and Social Capital in the OECD Countries. OECD Economic Studies No 33, 2001/II.

UCAS (2002a) UCAS/QCA Questionnaire on Curriculum 2000 provision in Schools and Colleges November 2001. http://www.ucas.com/candq/curr2000

UCAS (2002b) Analysis of offers involving curriculum 2000 qualifications for 2003 entry. http://www.ucas.com/candq/curr2000

Walker, I. and Yu Z. (2001) The Returns to Education: Evidence from the Labour Force Survey. DfES Research Report 313 


\section{Appendix}

Over/under-qualification ${ }^{10}$ represent a mismatch between the educational requirements of the job and the educational attainment of the job-holder. The returns to over-qualification can therefore be approached from two angles. One possibility is to keep qualifications held by workers constant and compare the wages of workers with the same qualifications in jobs with different educational requirements. Holding educational attainment constant, over-qualified workers have jobs requiring a lower educational level. Hence compared to having a job matching their qualifications overqualified workers are worse-off than adequately qualified ones and therefore their wages are expected to be lower. Following this approach Green and McIntosh (2002) find that over-qualified workers earn less than their adequately qualified counterparts. It has to be noted however that this approach holds qualifications possessed by workers constant and looks at returns obtained by the same qualifications in different jobs.

The alternative way to look at returns to over-qualification is to hold the educational requirements of the job constant and compare the wages of workers with different educational attainments in the same type of job. Holding job requirements constant, over-qualified workers have higher educational attainment than their adequately qualified peers. Within this framework, the presence of some positive return to overqualification will result in over-qualified workers earning more than workers who have qualifications matching the job requirement. Put differently, over-qualified workers will get some additional earnings out of holding qualifications even if they are not required for the job. Groot et al. (2000) survey the existing evidence on these two approaches for several countries. The evidence shows that controlling for educational attainment returns to over-education are negative while controlling for job requirements, returns to over-education are positive.

We reproduce in this appendix an analysis similar to the ones mentioned using qualifications instead of years of education. The Database we use is the 2001 Skills 
Survey in Britain (see Felstead et al, 2002) funded by the UK Government's Department for Education and Skills through the Centre for Skills Knowledge and Organisational Performance (SKOPE). To compare the outcomes of the different approaches we present in Table A three specifications. All specifications are based on a log-linear equation in the spirit of Mincer (1974).

Specification I replicates Table 10 in Green and McIntosh without controlling for over/under-skilling. The number of observations is therefore slightly higher and results not exactly matching but very similar. The main message of Specification I is that holding qualifications constant, over-qualified workers earn less than their adequately matched counterparts. Specification II does the same as the previous one holding job requirements constant. Since there is a positive significant effect of overeducation on wages, we can conclude that there are positive returns to over-education, holding job requirements constant. Specification III follows Groot et al. (2000) for the estimation of rates of return to overeducation (Specification I in Table 1). Since we are looking at over-qualifications, instead of years of over/under-education we include Levels of over/under qualification ${ }^{11}$. The variable Levels of Over-qualification takes values 1 to 5 , where 1 represents workers who have qualifications one level higher than those required for the job while the value 5 can only be taken by workers with a degree in jobs that require no qualifications. The message in column 6 is not much different from that in column 4: there are some positive returns to over-education in the British Labour market.

\footnotetext{
${ }^{10}$ We describe the analysis for over-qualification since this is our main concern. The reverse is true for under-qualification.

${ }^{11}$ For the definition of qualification levels in the Skills Survey, see Felstead et al (2002)
} 
TABLE A: Wage effects of over/under qualification.

\begin{tabular}{|c|c|c|c|c|c|c|}
\hline \multirow{2}{*}{$\begin{array}{l}\text { Dependent Variable: } \\
\text { Log of Hourly Pay }\end{array}$} & \multicolumn{2}{|c|}{ Specification I } & \multicolumn{2}{|c|}{ Specification II } & \multicolumn{2}{|c|}{ Specification III } \\
\hline & Coefficient & Std. Err. & Coefficient & Std. Err. & Coefficient & Std. Err. \\
\hline Over-qualified (yes/no) & $-0.172 * *$ & 0.015 & $0.090 * *$ & 0.015 & & \\
\hline Under-qualified (yes/no) & $0.177 * *$ & 0.018 & $-0.052 * *$ & 0.018 & & \\
\hline Levels of over-qualification & & & & & $0.072 * *$ & 0.009 \\
\hline Levels of under-qualification & & & & & $-0.027 *$ & 0.010 \\
\hline \multicolumn{7}{|l|}{ Qualifications held by worker } \\
\hline \begin{tabular}{|l|} 
Level 1 \\
\end{tabular} & $0.135^{* *}$ & 0.024 & & & & \\
\hline Level 2 & $0.217 * *$ & 0.021 & & & & \\
\hline Level 3 & $0.362 * *$ & 0.023 & & & & \\
\hline Level 4 & $0.564 * *$ & 0.026 & & & & \\
\hline Degree & $0.742 * *$ & 0.028 & & & & \\
\hline \multicolumn{7}{|l|}{ Qualifications required for job } \\
\hline $\begin{array}{r}\text { Level } 1 \\
\end{array}$ & & & $0.084 * *$ & 0.020 & $0.107 * *$ & 0.020 \\
\hline Level 2 & & & $0.217 * *$ & 0.020 & $0.257 * *$ & 0.019 \\
\hline Level 3 & & & $0.343 * *$ & 0.022 & $0.389 * *$ & 0.022 \\
\hline Level 4 & & & $0.586^{* *}$ & 0.026 & $0.642 * *$ & 0.026 \\
\hline Degree & & & $0.765^{* *}$ & 0.027 & $0.823 * *$ & 0.027 \\
\hline Female & $-0.141 * *$ & 0.014 & $-0.145 * *$ & 0.014 & $-0.144 * *$ & 0.014 \\
\hline Years of work experience & $0.026 * *$ & 0.002 & $0.024 * *$ & 0.002 & $0.024 * *$ & 0.002 \\
\hline Experience squared/100 & $-0.048 * *$ & 0.005 & $-0.044 * *$ & 0.005 & $-0.044 * *$ & 0.005 \\
\hline Married & $0.072 * *$ & 0.013 & $0.068 * *$ & 0.013 & $0.068 * *$ & 0.013 \\
\hline Has children & 0.019 & 0.015 & 0.017 & 0.015 & 0.018 & 0.015 \\
\hline Permanent job & 0.004 & 0.028 & -0.001 & 0.027 & 0.003 & 0.027 \\
\hline Fulltime job & $0.142 * *$ & 0.018 & $0.138 * *$ & 0.017 & $0.135^{* *}$ & 0.017 \\
\hline Ever do shift work & $-0.039 * *$ & 0.014 & $-0.032 *$ & 0.014 & $-0.034 *$ & 0.014 \\
\hline \multicolumn{7}{|l|}{ Workplace Size (employees) } \\
\hline $25-99$ & $0.078^{* *}$ & 0.017 & $0.075^{* *}$ & 0.017 & $0.074 * *$ & 0.017 \\
\hline $100-499$ & $0.120 * *$ & 0.018 & $0.119 * *$ & 0.018 & $0.117 * *$ & 0.018 \\
\hline $500-999$ & $0.147 * *$ & 0.034 & $0.139 * *$ & 0.034 & $0.139 * *$ & 0.033 \\
\hline $1000+$ & $0.137 * *$ & 0.019 & $0.120 * *$ & 0.019 & $0.123 * *$ & 0.019 \\
\hline \multicolumn{7}{|l|}{ Highest math qualification } \\
\hline \begin{tabular}{|r} 
Level 2 \\
\end{tabular} & $0.086 * *$ & 0.015 & $0.090 * *$ & 0.014 & $0.069 * *$ & 0.014 \\
\hline Level 3 & $0.165^{* *}$ & 0.029 & $0.175 * *$ & 0.029 & $0.149 * *$ & 0.029 \\
\hline Degree & $0.381 * *$ & 0.145 & $0.368^{*}$ & 0.145 & $0.351^{*}$ & 0.145 \\
\hline Constant & $1.147 * *$ & 0.048 & $1.164 * *$ & 0.047 & $1.120 * *$ & 0.047 \\
\hline Region Dummies & \multicolumn{2}{|c|}{ Yes } & \multicolumn{2}{|c|}{ Yes } & \multicolumn{2}{|c|}{ yes } \\
\hline Observations & \multicolumn{2}{|c|}{3595} & \multicolumn{2}{|c|}{3595} & \multicolumn{2}{|c|}{3595} \\
\hline R squared & \multicolumn{2}{|c|}{0.49} & \multicolumn{2}{|c|}{0.49} & \multicolumn{2}{|c|}{0.50} \\
\hline
\end{tabular}

Robust Standard Errors. ** significant at $1 \%$ level; * significant at 5\% level 